\title{
Determination of the Iodine Content of Some Commonly Consumed Foods in Zaria Metropolis, Nigeria, Using PCNAA and Sandell-Kolthoff Reaction
}

\author{
T. Muhammad, ${ }^{1}$ A. Uzairu, $^{2}$ M. S. Sallau, ${ }^{2}$ and M. O. A. Oladipo ${ }^{1}$ \\ ${ }^{1}$ Center for Energy Research and Training, Ahmadu Bello University, Zaria, Kaduna 810261, Nigeria \\ ${ }^{2}$ Chemistry Department, Ahmadu Bello University, Zaria, Kaduna 810261, Nigeria
}

Correspondence should be addressed to T. Muhammad; tmuhammad@abu.edu.ng

Received 26 April 2014; Accepted 2 July 2014; Published 21 July 2014

Academic Editor: Ioannis Pashalidis

Copyright (C) 2014 T. Muhammad et al. This is an open access article distributed under the Creative Commons Attribution License, which permits unrestricted use, distribution, and reproduction in any medium, provided the original work is properly cited.

\begin{abstract}
The Nigerian Research Reactor-1 was employed in the analysis of iodine in local food samples at an operating flux of $5.0 \times$ $10^{11} \mathrm{ncm}^{-2} \mathrm{~s}^{-1}$. Preconcentration neutron activation analysis (PCNAA) was compared against the most common spectroscopic (Sandell-Kolthoff reaction) technique, giving a concentration range of 0.295 to $2.960 \mathrm{mg} / \mathrm{Kg}$ and 0.264 to $2.725 \mathrm{mg} / \mathrm{Kg}$, respectively, with an average percentage deviation of $11.34 \%$ and a positive correlation between the methods at 0.89 . PCNAA and Sandell-Kolthoff spectroscopy of NIST 1548a reported values of $0.759 \pm 0.06 \mathrm{mg} / \mathrm{Kg}$ and $0.751 \pm 0.05$ with Student's $t$-test score of 1 and 0.95 and percentage standard deviation of 0 and $1.12 \%$, respectively.
\end{abstract}

\section{Introduction}

Iodine is an essential component of the thyroid hormones: thyroxine (T4) and triiodothyronine (T3), comprising 65 and 59 percent of their respective weights [1]. The thyroid hormones T4 and T3 regulate many key biochemical reactions, particularly protein synthesis and enzymatic activity. Major target organs are the developing brain, muscle, heart, pituitary, and kidney.

Without sufficient iodine, the body is unable to synthesize the thyroid hormones, and because they regulate metabolism in every cell of the body and play a role in virtually all physiological functions, iodine deficiency can have a devastating impact on health and well-being summarily termed iodine deficiency disorders (IDD). IDD is a major cause of retardation in children and was one of the contributing factors to high infant mortality [2]. Thyroid hormones, and therefore iodine, are essential for mammalian life.

The Nigerian Research Reactor-1 (NIRR-1) is the first in the country and its primary objective is to uplift the socioeconomic life of Nigerian citizen through effective utilization and research activities. It is meant to serve all categories in need of nuclear analytical and other related services. Irradiation and counting regimes for over 30 elements in both biological and geological matrices, including the essential elements $\mathrm{Fe}$, $\mathrm{Cr}, \mathrm{Co}, \mathrm{Cu}, \mathrm{Mn}$, and $\mathrm{Zn}$ have been standardized [3]. Recently, standard addition technique was employed to determine Selenium in cereals [4].

Accurate determination of iodine and in particular in biological matrix has always been difficult due to its low concentration and the inherent volatility of molecular iodine through sublimation at room temperature. However, iodine concentrations in biological matrix have been analyzed using a variety of techniques including spectroscopy [5-7], inductively coupled mass spectrometry [8-10], and ENAA [11-13] with the neutron activation analysis and mass spectrometry reporting the lowest detection limits and best sensitivities [13].

\section{Experimental}

The NIRR-1 is a low power nuclear reactor and is normally operated at $5.0 \times 10^{11} \mathrm{ncm}^{-2} \mathrm{~s}^{-1}$. Detailed descriptions of the reactor operation parameters are earlier reported $[3,14]$. Standard reference material (SRM) NIST 1548a (typical diet), 
NIST 1573a (tomato leaves), and NIST 1515 (apple leaves) were analysed along with the samples for quality control and assurance. Twenty-three food samples were collected through the guide of food frequency questionnaire, of which 8 are normally taken at breakfast and the rest serves as either lunch and/or dinner.

2.1. Preconcentration Neutron Activation Analysis [15]. About $0.5 \mathrm{~g}$ of dried and homogenized food sample was accurately weighted, and then the samples were digested with $7 \mathrm{~mL}$ ultrapure nitric acid in a closed system microwave oven at $1000 \mathrm{~W}$ for two minutes. After digestion, the system was cooled to room temperature and further cooled in ice-bath for one hour. The clear solution of digested sample was transferred into a beaker containing $1 \mathrm{~g}$ of hydrazine sulphate; the sample cup and its lid were washed with 3 portions of $5 \mathrm{~mL}$ aliquots of $5 \%$ hydrazine sulphate solution and deionized water. The digested sample and the washings are combined and diluted to $100 \mathrm{~mL}$. The $\mathrm{pH}$ of the solution was adjusted between 2 and 3 with 10\% ammonia solution. Iodine was coprecipitated with $1 \mathrm{~mL}$ each, of freshly prepared $0.05 \mathrm{M}$ bismuth sulphate and $0.25 \mathrm{M}$ thioacetamide. The precipitate was filtered by suction with $0.45 \mu \mathrm{m}$ membrane filter, dried and weight, and then packaged for irradiation. The samples were irradiated individually at the outer irradiation channel B4 of the NIRR-1 for 600 seconds and after a decay period of about 2 minutes the nuclide spectrum was obtained by counting the samples for 600 seconds using the $442 \mathrm{keV}$ gamma ray of ${ }^{128} \mathrm{I}$ at a height of $1 \mathrm{~cm}$ from the cap of a highpurity Germanium (HPGe) detector with a relative efficiency of $35 \%$ and a resolution (FWHM) of $1.93 \mathrm{keV}$ at $1332.5 \mathrm{keV}$ gamma ray line, and MAESTRO emulation software coupled to multichannel analyzer and associated electronic modules all made by EG\&G ORTEC. The spectra acquired were processed with the gamma ray spectrum analysis software WINSPAN 2004, and the results were obtained in $\mathrm{mg} / \mathrm{Kg}$.

2.2. Sandell-Kolthoff Reaction $[16,17]$. The digest was diluted to $25 \mathrm{~cm}^{3}$ and then analyzed for iodine with a UV/visible GBT Cintra 6 spectrophotometer at $420 \mathrm{~nm}$.

A standard curve using potassium iodate solution containing 0.5 to $10 \mathrm{ppm}$ iodine was prepared. The intensity of the developed color was measured at $420 \mathrm{~nm}$. The iodine concentration in the samples was calculated from the standard curve.

Quality control for iodine was maintained by including five reagent blanks to monitor contamination and estimate detection limits. Validation of the analytical techniques with each batch of samples analyzed was tested with the help of certified reference materials.

\section{Results and Discussion}

Significant challenge arises from the utilization of NIRR-1 in analysis of iodine in biological matrix, primary due to the low flux and external position of the cadmium lined irradiation channel. As such, the EINAA yield no result for iodine. Iodine 128 peaks at $442.9 \mathrm{keV}$ and $526 \mathrm{keV}$ were absent from the EINAA spectra of NIST 1548a and NIST

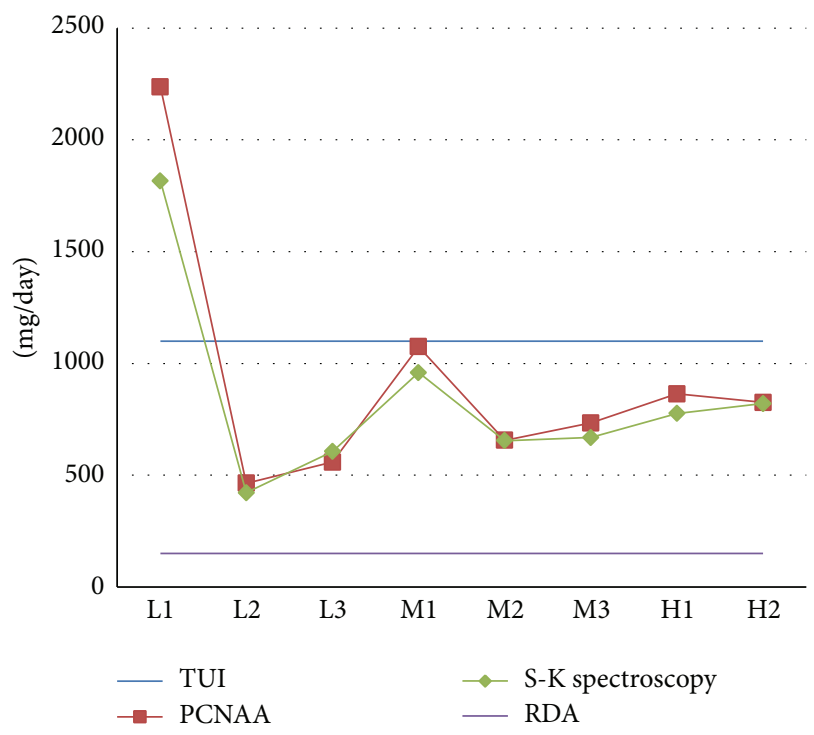

FIGURE 1: Iodine daily intake.

1515. However, both peaks were observed from the same NIST SRM spectra by employing PCNAA. The presence of, in most biological materials, large concentrations of elements such as sodium, chorine, manganese, and in some cases aluminum inhibits the determination of iodine by NAA which is often of microconcentration. The EINAA annihilates the thermal neutrons that largely excite the interfering nuclides. However, due to the low concentration of iodine in the SRMs (and biological samples especially food) coupled with the fact that NIRR-1 is a low flux reactor with $4.22 E+04$ and $2.38 E+$ $10 \mathrm{ncm}^{-2} \mathrm{~s}^{-1}$ thermal and epithermal fluxes, respectively, at the Al cadmium lined irradiation channel, determination of iodine by EINAA was impractical.

It is observed from Table 1 that the PCNAA analysis results have better accuracy, while S-K spectroscopy has slightly better precision. The $t$-test for NIST 1515 was not calculated because its value in the certificate is reported as informative (not certified).

Based on the local economy, the food samples were grouped into low (L), medium $(\mathrm{M})$, and high $(\mathrm{H})$ priced. L: food cost is less than US $\$ 1.5, \mathrm{M}$ : food cost is between US $\$ 1.5$ and US \$3.5, and $\mathrm{H}$ : food cost is more than US \$3.5; the first numeral gives the identity of the sampling point, while the last numeral is $1=$ breakfast, $2=$ lunch, and $3=$ dinner.

The food samples are whole meals served in restaurants and local eateries across Zaria, Nigeria. Tuwo is a typical Northern Nigerian food; it is a stiff paste made from numerous cereals: Shinkafa, rice, Masara, and corn, while Waina is a pan fry corn paste.

The foods analysed have sufficient iodine to furnish the recommended daily intake (Figure 1 ). In the case of sample RL 1-3 (Table 2), the iodine content is twice the upper tolerable intake limit of $1100 \mu \mathrm{g} /$ day [18]. In most other cases, the iodine consumption per day is approaching the upper tolerable intake limit, and prolong consumption of such foods may not be suitable. 
TABLE 1: Comparison of SRM certified values and this work.

\begin{tabular}{lccccccc}
\hline SRMs & PCNAA $(\mathrm{mg} / \mathrm{Kg})$ & \% SD & $t$-test & S-K spectroscopy $(\mathrm{mg} / \mathrm{Kg})$ & $\%$ SD & $t$-test & SRM certified value $(\mathrm{mg} / \mathrm{Kg})$ \\
\hline NIST 1548a & $0.759 \pm 0.06$ & 0 & 1 & $0.751 \pm 0.05$ & 1.12 & 0.95 & $0.759 \pm 0.103$ \\
NIST 1515 & $0.30 \pm 0.07$ & 0 & & $0.286 \pm 0.01$ & 6.99 & 0.3 \\
\hline
\end{tabular}

TABLE 2: Iodine content of some commonly consumed local foods.

\begin{tabular}{|c|c|c|c|c|c|c|c|}
\hline \multirow{2}{*}{$\mathrm{S} / \mathrm{N}$} & \multicolumn{2}{|c|}{ SAMPLE } & \multicolumn{2}{|c|}{ PCNAA } & \multirow{2}{*}{$\begin{array}{l}\text { Percentage } \\
\text { deviation }\end{array}$} & \multicolumn{2}{|c|}{ S-K method } \\
\hline & Code & Food items & $\begin{array}{l}\text { Iodine } \\
\text { (mg/Kg) }\end{array}$ & $\begin{array}{l}\text { Iodine in } \\
\text { food }(\mu \mathrm{g})\end{array}$ & & $\begin{array}{l}\text { Iodine } \\
\text { (mg/Kg) }\end{array}$ & $\begin{array}{l}\text { Iodine in } \\
\text { food }(\mu \mathrm{g})\end{array}$ \\
\hline 1 & L 1-1 & Fried beans cake and pap & $0.30 \pm 0.05$ & 62.06 & 10.51 & $0.26 \pm 0.02$ & 55.54 \\
\hline 2 & L $1-2$ & Rice and beans meat, stew & $1.89 \pm 0.08$ & 118.41 & 36.83 & $1.19 \pm 0.03$ & 74.80 \\
\hline 3 & L 1-3 & Tuwo Masara, dry okra sauce & $9.60 \pm 0.16$ & 2056.23 & 18.01 & $7.94 \pm 0.29$ & 1685.98 \\
\hline 4 & L 2-1 & Fried sweet potato and gruel & $0.75 \pm 0.06$ & 157.07 & 15.01 & $0.63 \pm 0.11$ & 133.49 \\
\hline 5 & L 2-2 & Rice, spaghetti, and vegetables & $1.34 \pm 0.08$ & 307.64 & 6.35 & $1.25 \pm 0.06$ & 288.11 \\
\hline 6 & L 2-3 & Tuwo Masara, vegetable soup & BDL & 0.00 & & BDL & $\mathrm{BDL}$ \\
\hline 7 & L 3-1 & Moi-Moi & $0.81 \pm 0.10$ & 125.75 & 3.85 & $0.78 \pm 0.02$ & 120.92 \\
\hline 8 & L 3-2 & Jellop rice and beans & $1.16 \pm 0.08$ & 261.82 & 3.78 & $1.12 \pm 0.02$ & 251.92 \\
\hline 9 & L 3-3 & Tuwo Masara, dry okra sauce & $0.78 \pm 0.06$ & 171.40 & 36.16 & $1.09 \pm 0.02$ & 233.38 \\
\hline 10 & M 1-1 & Potato chips, eggs, liver sauce & $1.36 \pm 0.07$ & 341.66 & 15.11 & $1.16 \pm 0.03$ & 290.03 \\
\hline 11 & M 1-2 & Fried rice, pea, carrot, cabbage & $1.61 \pm 0.08$ & 270.26 & 3.78 & $1.55 \pm 0.02$ & 260.04 \\
\hline 12 & M 1-3 & Pounded yam, vegetables soup & $1.40 \pm 0.07$ & 463.20 & 11.76 & $1.22 \pm 0.02$ & 408.73 \\
\hline 13 & M 2-1 & Waina da Taushe & $1.29 \pm 0.07$ & 332.48 & 4.41 & $1.24 \pm 0.02$ & 317.83 \\
\hline 14 & M 2-2 & White rice,vegetables salad & $0.89 \pm 0.09$ & 168.39 & 5.38 & $0.94 \pm 0.03$ & 177.44 \\
\hline 15 & M 2-3 & Tuwo Shinkafa, Egusi soup & $1.13 \pm 0.22$ & 155.57 & 2.58 & $1.16 \pm 0.02$ & 159.57 \\
\hline 16 & M 3-1 & Potato chips, eggs, beef sauce & $0.55 \pm 0.07$ & 141.17 & 18.84 & $0.45 \pm 0.03$ & 114.58 \\
\hline 17 & M 3-2 & Fried rice, pea, onion, beef & $1.31 \pm 0.06$ & 167.12 & 2.44 & $1.28 \pm 0.01$ & 163.05 \\
\hline 18 & M 3-3 & Tuwo Shinkafa, Egusi soup & $2.96 \pm 0.09$ & 425.26 & 7.94 & $2.73 \pm 0.15$ & 391.50 \\
\hline 19 & H 1-1 & French fries, eggs, liver sauce & $1.18 \pm 0.07$ & 191.96 & 2.89 & $1.14 \pm 0.09$ & 186.41 \\
\hline 20 & H $1-2$ & Savory rice, vegetables, chicken & $0.42 \pm 0.04$ & 110.63 & 34.53 & $0.27 \pm 0.02$ & 72.42 \\
\hline 21 & H 1-3 & Semovita, vegetables soup & $2.09 \pm 0.08$ & 561.88 & 7.89 & $1.93 \pm 0.04$ & 517.52 \\
\hline 22 & H 2-2 & Fried rice and salad, chicken & $2.44 \pm 0.08$ & 453.13 & 0.04 & $2.44 \pm 0.03$ & 452.95 \\
\hline 23 & H 2-3 & Pounded yam, vegetables soup & $1.27 \pm 0.04$ & 372.79 & 1.41 & $1.26 \pm 0.02$ & 367.52 \\
\hline
\end{tabular}

Iodine analysis reported considerable deviation between the two methods in some sample (Table 2), with Pearson correlation at 0.95 . However, both methods may be considered relatively accurate (Figure 2), with the PCNAA reporting better accuracy in the SRM analysis.

The PCNAA result ranges from 0.295 to $2.960 \mathrm{mg} / \mathrm{Kg}$, while that of spectroscopy is from 0.264 to $2.725 \mathrm{mg} / \mathrm{Kg}$. However, sample L 1-3 at Table 2 has abnormal high iodine content at 9.680 and $7.937 \mathrm{mg} / \mathrm{Kg}$ from the PCNAA and spectroscopy, respectively, which results in about twice the tolerable upper intake level. Retrace of sample collection and processing indicates no possible contamination avenue and also no batch member presents such abnormality.

In most cases, the PCNAA concentrations from Table 2 are slightly more than those of the spectroscopy except in two of the samples. There is no indication that any meal (i.e., breakfast, lunch, or dinner) furnished more iodine than the others. Likewise, similar food items reported unrelated iodine concentration.

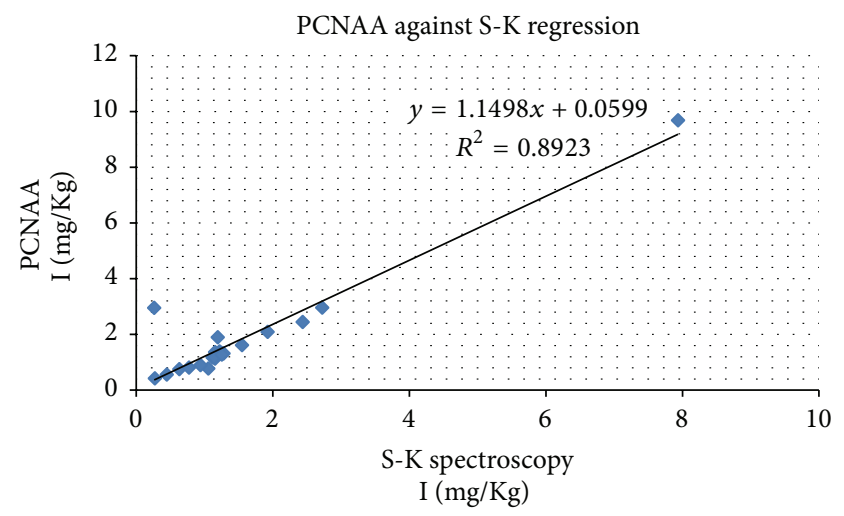

Figure 2: Comparison between PCNAA and spectroscopy.

Samples L 1-3 and L 3-3 (Table 2) are similar in composition, but while L 1-3 reported the highest concentration 
(9.68 mg/Kg), L 3-3 was the only sample to report concentration below detection limit. These indicate that iodine in foods is supplied not by the main ingredients but by the iodized salt used. Iodine concentrations were reported to have ranges of 22.2 to $74.1 \mathrm{mg} / \mathrm{Kg}$ and 12.7 to $49.7 \mathrm{mg} / \mathrm{Kg}$ in packaged and exposed table salts, at Owerri, southeastern Nigeria, with a mean of $47.80 \mathrm{ppm}$ and $26.98 \mathrm{ppm}$, respectively [19]. Similar report indicates iodine concentrations of $26.31 \mathrm{mg} / \mathrm{Kg}$ to $106.82 \mathrm{mg} / \mathrm{Kg}$ in seven brands with mean of $69.01 \mathrm{mg} / \mathrm{Kg}$ and $58.16 \mathrm{mg} / \mathrm{Kg}$ to $105.75 \mathrm{mg} / \mathrm{Kg}$ with mean of $71.34 \mathrm{mg} / \mathrm{Kg}$ in eateries across Yola, northeastern Nigeria [20].

\section{Conclusion}

The determination of iodine content of commonly consumed foods in Zaria metropolis by preconcentration neutron activation analysis and Sandell-Kolthoff spectroscopy report results ranging from 0.295 to $2.960 \mathrm{mg} / \mathrm{Kg}$ and 0.264 to $2.725 \mathrm{mg} / \mathrm{Kg}$, respectively.

While the spectroscopy is cheap with little labour, the accuracy of its result is not as excellent as that of the neutron activation analysis.

The foods analyzed supplied the recommended daily allowance for iodine and in some cases approaching the upper tolerable limit.

Iodine consumption by different income group is not significantly different since the major avenue for iodination for foods is iodized salt and is accessible to all at low cost.

\section{Conflict of Interests}

The authors declare that there is no conflict of interests regarding the publication of this paper.

\section{Acknowledgment}

The authors appreciate and commend the effort of the management and staff of the Center for Energy Research and Training, Ahamdu Bello University, Zaria, especially those of Nuclear Science and Technology Section, for their assistance in various capacities in making this work possible.

\section{References}

[1] O. M. Ahmed, A. W. El-Gareib, A. M. El-bakry, S. M. Abd El-Tawab, and R. G. Ahmed, "Thyroid hormones states and brain development interactions," International Journal of Developmental Neuroscience, vol. 26, no. 2, pp. 147-209, 2008.

[2] Iodine deficiency, International Council for the Control of Iodine Deficiency Disorders, 2011, http://www.iccidd.org/.

[3] S. A. Jonah, I. M. Umar, M. O. A. Oladipo, G. I. Balogun, and D. J. Adeyemo, "Standardization of NIRR-1 irradiation and counting facilities for instrumental neutron activation analysis," Applied Radiation and Isotopes, vol. 64, no. 7, pp. 818-822, 2006.

[4] Y. A. Yamusa, Y. A. Ahmed, Y. Musa, S. A. Kasim, M. Tukur, and S. Bilal, "Multi-elemental analysis of local millet and wheat by instrumental neutron activation analysis using NIRR1 facility," International Journal of Multidisciplinary Sciences and Engineering, vol. 4, no. 7, pp. 9-13, 2013.
[5] O. M. Trokhimenko and V. N. Zaitsev, "Kinetic determination of iodide by the Sandell-Kolthoff reaction using diphenylamine4-sulfonic acid," Journal of Analytical Chemistry, vol. 59, no. 5, pp. 491-494, 2004.

[6] R. Gurkan, N. Bicer, M. H. Ozkan, and M. Akcay, "Determination of trace amounts of iodide by an inhibition kinetic spectrophotometric method," Turkish Journal of Chemistry, vol. 28, pp. 181-191, 2004.

[7] M. R. Shishehbore, A. Sheibani, and R. Jokar, "Kinetic spectrophotometric determination of trace amounts of iodide in food samples," Analytical Sciences, vol. 26, no. 4, pp. 497-501, 2010.

[8] J. W. Gramlich and T. J. Murphy, "Determination of trace level iodine in biological and botanical reference materials by isotope dilution mass spectrometry," Journal of Research of the National Institute of Standards and Technology, vol. 94, no. 4, pp. 215-220, 1989.

[9] P. A. Fecher, I. Goldmann, and A. Nagengast, "Determination of iodine in food samples by inductively coupled plasma mass spectrometry after alkaline extraction," Journal of Analytical Atomic Spectrometry, vol. 13, no. 9, pp. 977-982, 1998.

[10] J. H. Lee, O. Ji, M. Song et al., "Determination of urinary iodine concentration by inductively coupled plasma-mass spectrometry in thyroid cancer patients on low-iodine diet," Korean Journal of Laboratory Medicine, vol. 30, no. 4, pp. 351-356, 2010.

[11] T. Sato and T. Kato, "Estimates of iodine in biological materials by epithermal neutron activation analysis," Journal of Radioanalytical Chemistry, vol. 68, no. 1-2, pp. 175-180, 1982.

[12] T. A. Nichols, J. S. Morris, V. L. Spate et al., "Longitudinal study of iodine in market milk and infant formula via epiboron neutron activation analysis," Journal of Radioanalytical and Nuclear Chemistry, vol. 236, no. 1-2, pp. 65-69, 1998.

[13] J. Kučera, G. V. Iyengar, Z. Řanda, and R. M. Parr, "Determination of iodine in Asian diets by epithermal and radiochemical neutron activation analysis," Journal of Radioanalytical and Nuclear Chemistry, vol. 259, no. 1, pp. 505-509, 2004.

[14] W. B. Stroube Jr., W. C. Cunningham, and G. J. Lutz, "Analysis of foods for iodine by epithermal neutron activation analysis," Journal of Radioanalytical and Nuclear Chemistry, vol. 112, no. 2, pp. 341-346, 1987.

[15] V. A. Maihara, P. L. C. Moura, D. I. T. Fávaro, and M. B. A. Vasconcellos, "Assessment of iodine content in Brazilian duplicate portion diets and in table salt," Journal of Radioanalytical and Nuclear Chemistry, vol. 278, no. 2, pp. 391-393, 2008.

[16] A. Chatt and R. R. Rao, "Microwave acid digestion and preconcentration neutron activation analysis of biological and diet samples for iodine," Analytical Chemistry, vol. 63, no. 13, pp. 1298-1303, 1991.

[17] E. B. Sandell and I. M. Kolthoff, "Micro determination of iodine by a catalytic method," Mikrochimica Acta, vol. 1, no. 1, pp. 9-25, 1937.

[18] J. Tyndall, V. Okaye, M. Ameh et al., "Determination of iodide content of table salts in Nigeria," European Chemical Bulletin, vol. 2, no. 6, pp. 324-327, 2013.

[19] P. W. Fischer, M. R. L'Abbé, and A. Giroux, "Colorimetric determination of total iodine in foods by iodide-catalyzed reduction of Ce+4.," Journal - Association of Official Analytical Chemists, vol. 69, no. 4, pp. 687-689, 1986.

[20] C. O. Ujowundu, F. N. Kalu, R. N. Nwaoguikpe, K. O. Igwe, R. I. Okechukwu, and T. I. N. Ezejiofor, "Salt iodization and thyroid function of pregnant women in early pregnancy in Owerri-southeast Nigeria," International Research Journal of Biochemistry and Bioinformatics, vol. 1, no. 10, pp. 248-256, 2011. 

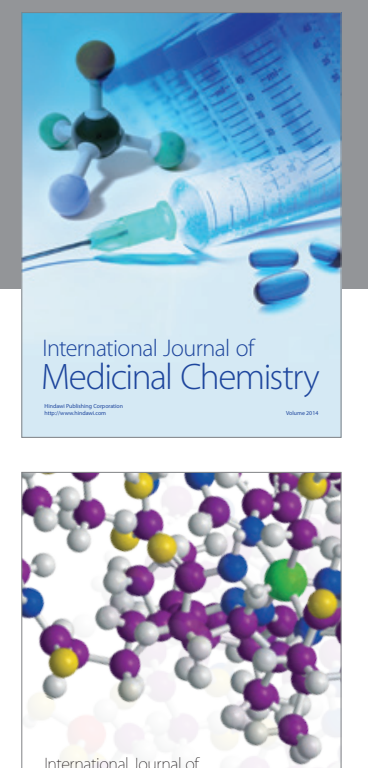

\section{Carbohydrate} Chemistry

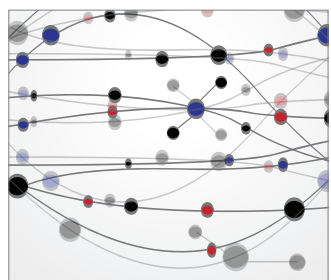

The Scientific World Journal
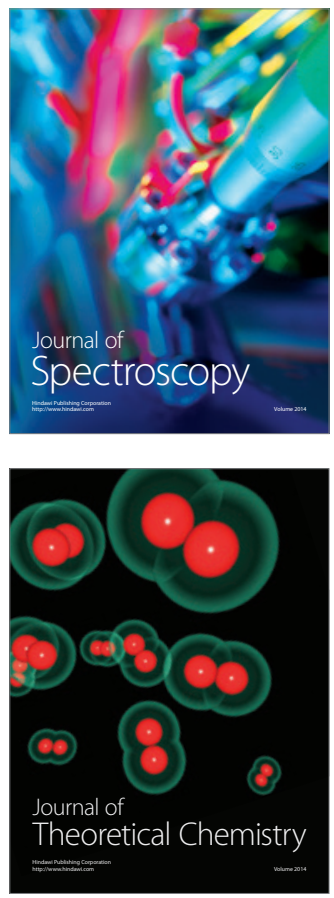
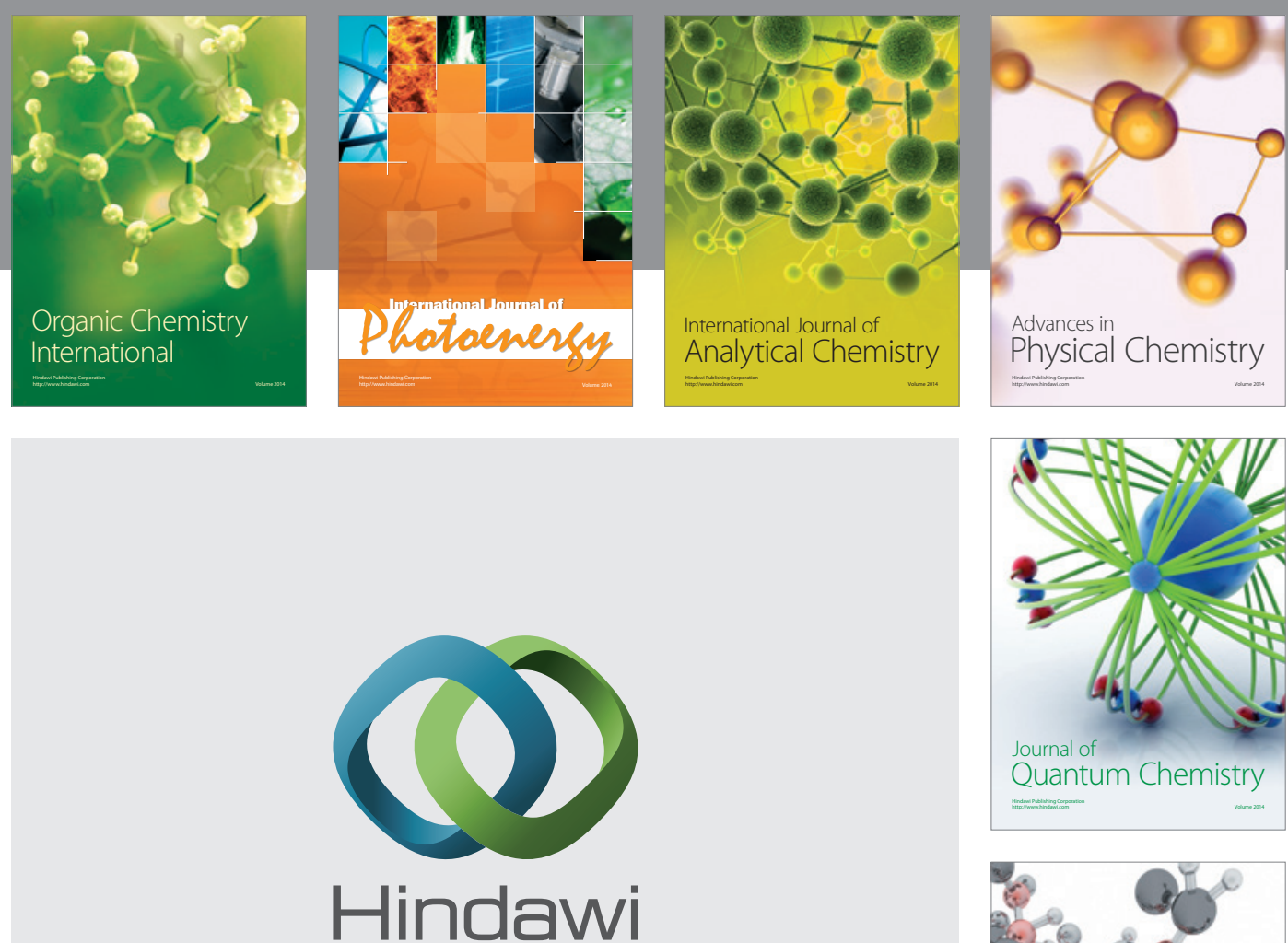

Submit your manuscripts at

http://www.hindawi.com

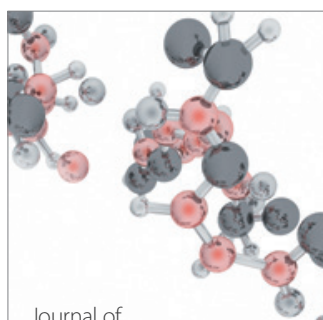

Analytical Methods

in Chemistry

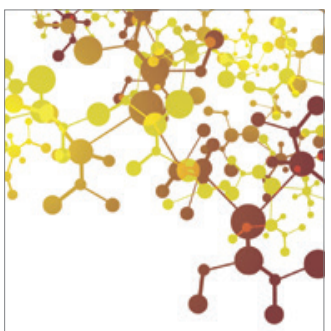

Journal of

Applied Chemistry

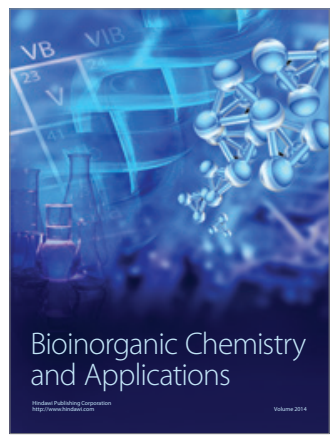

Inorganic Chemistry
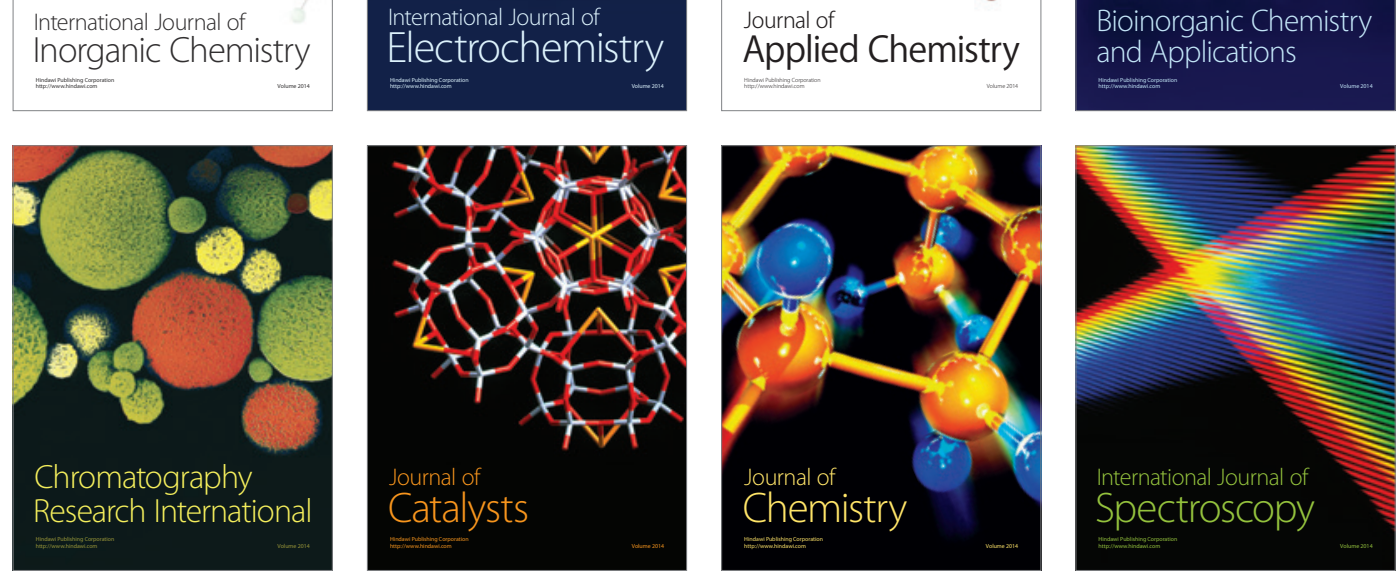